\title{
Hubungan Verifikasi Laporan Keuangan Terhadap Tindakan Suap Pada Usaha Kecil dan Menengah
}

\section{Minarti Martria Leny*}

Fakultas Ekonomikas Dan Bisnis, Universitas Kristen Satya Wacana

\section{A R T I C L E I N F 0}

\section{Article history:}

Received 19 August 2019 Received in revised form 16 September 2019 Accepted 15 October 2019 Available online 30 November 2019

\section{Kata Kunci:}

Verifikasi Laporan

Keuangan, Suap, UMK

Keywords:

Verification of Financial

Statements, Bribery, SMEs

\begin{abstract}
A B S T R A K
Verifikasi laporan keuangan adalah hal yang paling penting untuk setiap usaha yang berfungsi untuk memastikan bahwa laporan keuangan perusahaan telah memenuhi karakteristik laporan keuangan yang meliputi handal, relevan, dapat dipahami dan dapat dibandingkan. Namun hal tersebut jarang dilakukan oleh UMK. Penelitian ini bertujuan untuk mengetahui apakah ada hubungan antara verifikasi laporan keuangan dengan tindakan suap pada UMK. Metode pada penelitian ini menggunakan uji regresi probit yang bertujuan untuk mengetahui hubungan antar variabel, hubungan antar variabel dalam penilitian ini yaitu hubungan verifikai laporan keuangan terhadap tindakan suap pada UMK. Sumber data yang digunakan dalan penelitian ini yaitu data sekunder yang diperoleh dari The World bank Indonesia Enterprise Survey yang dilakukan pada tahun 2015. Hasil penelitian ini memberikan bukti bahwa UMK yang sudah melakukan verifikasi atas laporan keuangan tidak signifikan terhadap tindakan suap.
\end{abstract}

\section{A B S T R A C T}

Verification of financial statements is one of the most prominent things in business that serves to ensure that the company's financial statements meet the high-quality requirements of a report which include reliable, relevant, understandable and comparable. These requirements, however, are rarely found is SMEs.. This study aims to explore the relationship between verification of financial statements which involves bribery in SME context. The method employed in this study is quantitative approach using SPSS in performing analyses namely probit test. Both tests attempt to determine the relationship between variables, such as the relationship between verification of financial statements and bribery in SMEs. The data source used in this study is secondary data obtained from The World Bank Indonesia Enterprise Survey conducted in 2015. The results of this study provide evidence that SMEs that have verified financial statements are least likely to be involved in bribery.

*Corresponding author.

E-mail addresses: minartimatrialeny@gmail.com (Minarti Matria Leny) 


\section{Pendahuluan}

Korupsi merupakan suatu masalah yang banyak dihadapi di dunia. Menurut The World Bank (2004) korupsi adalah penyalahgunaan jabatan untuk keuntungan pribadi. Sedangkan menurut Healy \& Serafeim (2016) korupsi telah diidentifikasi sebagai faktor utama yang menghambat pertumbuhan ekonomi. Salah satu tindakan korupsi yang sering terjadi dalam dunia bisnis adalah suap (Cuervo \& Cazurra, 2007).

Di banyak negara terutama di negara berkembang, perusahaan-perusahan terkadang membayar suap kepada pejabat pemerintah. Survei Transparency International (2011) mengutarakan bahwa sekitar 450 (15\%) dari 3.000 eksekutif perusahaan di 28 negara dunia pernah melakukan suap ketika berhubungan dengan pelayan publik atau pemerintah. Ada banyak faktor yang mempengaruhi perusahaan untuk melakukan suap salah satunya karena kurangnya perhatiaan perusahaan terhadap laporan keuangan. Farooq \& Shehata (2018) menyatakan bahwa suap lebih nyata dapat terjadi di lingkungan perusahaan yang tekanannya lebih tinggi untuk terlibat dalam praktik suap.

Praktek enyuapan oleh perusahaan akan memberi dampak negatif bagi perusahaaan dimana penyuapan akan mengurangi arus modal dan perkembangan keuangan serta politik dalam perusahaan (Cuervo \& Cazurra (2007). Begitupun Wu (2009) menyatakan bahwa penyuapan dapat meningkatkan biaya perusahaan dikarenakan perusahaan akan mengeluarkan biaya yang tidak terduka atau tidak dianggarkan sebelumnya sehinnga biaya tersebut membuat laba perusahaan turun. Hal ini selaras dengan pendapat Sohail (2014) yang mengkategorikan suap sebagai biaya, karena terjadinya pembayaran pajak yang tidak disengaja keluar kepada pemerintah. Tindakan korupsi yang terjadi di suatu perusahaan dapat menjadi pemicu terjadinya kerugian, baik kerugian finansial maupun non-finansial bahkan berujung pada pailit.

Salah satu cara yang yang dapat dilakukan perusahaan dalam meminimalisasi tindakan suap yang terjadi ialah dengan memperhatikan kualitas laporan keuanagn yang dibuat. Menurut Astuti (2014) Laporan keuangan memiliki peran dalam kelangsungan hidup suatu entitas bisnis dalam mengkomunikasikan informasi keuangan kepada pihak eksternal perusahaan. Kualitas informasi dalam laporan keuangan dapat dinilai melalui kegiatan verifikasi laporan keuangan. Farooq \& Shehata (2018) menyatakan bahwa kegiatan verifikasi merupakan proses konfirmasi yang meyakinkan keberadaan aset dan liabilitas yang tertera di laporan keuangan. Kegiatan verifikasi laporan keuangan dilakukan untuk memastikan bahwa laporan keuangan perusahaan telah memenuhi karakteristik laporan keuangan yang meliputi handal, relevan, dapat dipahami dan dapat dibandingkan.

Verifikasi laporan keuangan dilakukan oleh auditor, baik auditor internal maupun eksternal, Meskipun umumnya verifikasi laporan keuangan dilakukan oleh auditor eksternal. Penelitian Khalil (2015) membuktikan bahwa perusahaan akan mengurangi penyuapan kepada pejabat publik jika laporan keuangan di audit oleh audit eksternal. Hal ini dikarenakan auditor eksternal mempunyai independensi terhadap perusahan yang diaudit. Auditor eksternal akan memberikan opini tentang laporan keuangan perusahaan, dimana opini dari auditor eksternal ini dibutuhkan oleh pengguna laporan keuangan untuk pengambilan keputusan.

Namun masih banyak perusahaan yang tidak menyadari akan pentingnya verifikasi atas laporan keuangan, khususnya pada perusahan usaha kecil dan menegah (UKM). Farooq \& Shehata (2018) menyatakan bahwa perusahaan UKM cenderung sering mengalami suap diakibatkan tidak pernah melakukan verifikasi laporan keuangan.

Dengan demikian, penilitan ini bertujuan ingin mengetahui apakah UKM yang melakukan verifikasi atas laporan keuangan akan membayar suap lebih rendah daripada UMK yang tidak melakukan verifikasi laporan keuangan.. Penelitian ini menggunakan data Indonesia karena saat ini Indonesia merupakana salah satu negara yang masih memiliki indeks korupsi cukup tinggi. Transparancy Interational (2018) menunjukkan Indonesia berada di peringkat 89 dari 180 negara dengan skor 38 padahal pada tahun 2014 Indonesia berada pada peringkat 88. Meskipun sekarang ada aktivitas yang sangat gencar dilakukan untuk mengurangi korupsi, namun ternyata korupsi masih banyak terjadi sehingga penelitian dianggap relevan menggunakan data Indonesia.

Berdasarkan penjelasan diatas, Penelitian ini diharapkan dapat dapat memberikan informasi kepada UKM akan peran verifikasi laporan keuangan dalam mengurangi pembayaran suap dan apakah dampak verifikasi laporan keuangan terhadap suap siginifikan atau tidak. 


\section{Metode}

Penelitian ini menggunakan data sekunder yang diperoleh dari hasil survei The World bank Indonesia Enterprise Survey yang dilakukan pada tahun 2015 dengan jumlah sampel awal 1.320 responden yang tersebar di sembilan provinsi di Indonesia. Survei yang dilakukan tersebut menggunakan usaha kecil dan menengah sebagai objeknya, karena usaha sektor kecil dan menengah di Indonesia sedang mengalami perkembangan yang pesat. Di sisi lain penelitian dengan menggunakan usaha sektor kecil dan menengah sangat cocok dilakukan di negara - negara berkembang seperti Indonesia karena kontribusinya usaha tersebut. Penentuan objek usaha yang termasuk dalam kriteria usaha kecil dan menengah sendiri didasarkan pada kriteria yang telah ditentukan oleh Badan Pusat Statistik yang menggolongkan usaha berdasarkan jumlah tenaga kerja.

Variabel independen yang digunakan dalam penilitian ini adalah verifikasi laporan keuangan (Ver) yang bersifat mempengaruhi variabel dependen pada penilitian ini. Variabel independen ini merujuk pada pertanyaan K.21 pada survei yang menanyakan apakah perusahaan melakukan verifikasi laporan keuangan tahunan dan diperiksa oleh auditor eksternal?. Pertanyaan tersebut menghasilkan data biner, yaitu angka 1 (satu) untuk responden yang menjawab "ya", sedangkan angka 0 (nol) untuk responden yang menjawab "tidak", sedangkan untuk responden yang tidak menjawab akan dihapus dari analisis.

Adapun variabel yang dipengaruhi atau varibel dependen dalam penilitian ini adalah korupsi (suap) yang terjadi pada UKM. Hal ini merujuk pada pertanyaan J.7 dalam survei yang menanyakan apakah perusahaan melakukan pembayaran atau memberi hadiah non formal kepada pejabat publik? Pertanyaan tersebut menghasilkan data biner angka 0 (nol) untuk responden yang menjawab "ya", sedangkan angka 1 (satu) untuk responden yang menjawab "tidak", sedangkan untuk responden yang tidak menjawab akan dihapus dari analisis.

Penelitian ini menggunakan 2 (dua) variabel kontrol yaitu umur perusahaan (Age) dan ukuran perusahaan (Size). Umur perusahaan didapatkan dari tahun survei (2015) dikurangi dengan tahun berdirinya UMK tersebut. Selanjutnya ukuran perusahaan menggunakan jumlah karyawan sebagai pengukurannya. Dikatakan bahwa perusahaan besar lebih kecil kemungkinannya menyuap untuk mendapatkan kontrak pemerintah karena sumber daya dan jaringannya yang signifikan.

Pengujian hipotesis pada penelitian ini menggunakan uji regresi probit untuk menganalisis datanya. Penulis menggunakan uji regresi probit untuk mengetahui hubungan antar variabel dalam penilitian ini yaitu hubungan verifikai laporan keuangan terhadap tindakan suap.

\section{Hasil dan pembahasan}

\section{Statistika Deskriptif}

Jumlah sampel yang semula adalah 9 provinsi dengan jumlah responden 1.320, tetapi yang memenuhi kriteria dalam penelitian ini hanya 670 responden. Beberapa kriteria yang digunakan dalam penelitian ini yaitu responden yang menjawab apakah perusahaan melakukan verifikasi laporan keuangan tahunan, apakah perusahaan melakukan pembayaran atau memberi hadiah non formal kepada pejabat publik. Beberapa kriteria lain yang harus diisi oleh responden seperti jumlah tenaga kerja, umur perusahaan dan ukuran perusahaan. Sedangkan yang tidak memenuhi kriteria dalam penelitian ini yaitu responden yang tidak menjawab pertanyaan tersebut akan dihapus.

Tabel 1. Jumlah Responden per Provinsi

\begin{tabular}{clc}
\hline No. & \multicolumn{1}{c}{ Negara } & Jumlah Sampel \\
\hline 1. & Bali & 60 \\
2. & Banten & 56 \\
3. & DKI Jakarta & 71 \\
4. & Jawa Barat & 73 \\
5. & Jawa Tengah & 118 \\
6. & Jawa Timur & 156 \\
7. & Lampung & 40 \\
8. & Sulawesi Selatan & 61 \\
9. & Sumatera Utara & 35 \\
& Total & 670 \\
\hline
\end{tabular}


Tabel 2. Jumlah Responden Melakukan Verifikasi

\begin{tabular}{lcc}
\hline & & Frequency \\
\hline Ukuran perusahaan & Small & 338 \\
& Medium & 332 \\
Verifikasi & No & 587 \\
& Yes & 83 \\
\hline
\end{tabular}

Tabel 3. Jumlah Respoden Melakukan Suap

\begin{tabular}{lccc}
\hline & & N & Percent \\
\hline Suap & No & 636 & $94.9 \%$ \\
& Yes & 34 & $5.1 \%$ \\
& Total & 670 & $100.1 \%$ \\
\hline
\end{tabular}

Dari seluruh responden yang berjumlah 670 responden, terdapat 83 yang tidak mengaku melakukan verifikasi atas laporan keuangan dan sebanyak 636 (94.9\%) yang mengaku tidak melakukan pembayaran atau memberi hadiah non formal kepada pejabat publik. Sedangkan responden yang mengaku melakukan verifikasi atas laporan keuangan 83 dan yang mengaku melakukan pembayaran atau memberi hadiah non formal kepada pejabat public sebanyak 34 (5.1\%).

Tabel 4. Statistik Deskriptif

\begin{tabular}{lccc}
\hline & N & Mean & Std. Deviation \\
\hline Suap & 670 & 0.05 & 0,220 \\
Verifikasi & 670 & 0,12 & 0,330 \\
Ukuran Perusahaan & 670 & 1,50 & 0,500 \\
Umur Perusahaan & 670 & 18,47 & 10,588 \\
\hline
\end{tabular}

\section{Analisis Probit}

Analisis dalam penelitian ini uji regresi probit. Regresi probit digunakan untuk menguji hubungan variabel suap dengan memasukkan umur perusahaan dan ukuran perusahaan sebagai variabel kontrolnya. Hasil dari uji regresi probit Tabel 5 menunjukan bahwa hubungan antara verifikasi laporan keuangan dengan memasukan ukuran perusahaan dan umur perusahaan sebagai variabel kontrolnya tidak signifikan terhadap tindakan suap [Sig = alpha $<0,05]$

Tabel 5. Persamaan Model Regresi

\begin{tabular}{lll}
\hline Likelihood Rasio Chi-Square & Df & Sig \\
\hline 1.805 & 3 & .614 \\
\hline
\end{tabular}

Selanjutnya Tabel 6 menjelaskan korelasi antar variabel dependen dengan variabel independen serta variabel kontrol. Tabel 6 menunjukkan bahwa verifikasi laporan keuangan memiliki korelasi positif dengan suap tetapi tidak signifikan [B=.164/Sig=.482] yang artinya semakin kecil peluang adanya verifikasi maka semakin besar peluang akan terjadi suap. Selanjutnya, ukuran perusahaan juga menunjukkan korelasi positif dengan suap tetapi tidak signifikan [B=.168/Sig=.330] yang artinya semakin kecil ukuran perusahaan maka semakin besar peluang untuk terjadinya suap. Sedangakn umur persusahaan tidak memiliki korelasi positif dengan suap dan tidak signifikan [B=-.003/Sig=.733] artinya peluang adanya suap dari segi umur perusahaan sangat kecil dan tidak signifikan maka usia bisa diabaikan dalam persamaan regresi ini.

Tabel 6: Persamaan korelasi Regresi

\begin{tabular}{lcc}
\hline \multicolumn{1}{c}{ Parameter } & B & Sig \\
\hline Verifikasi laporan keuangan & .164 & .482 \\
Ukuran perusahaan & .168 & .330 \\
Usia perusahaan & -.003 & .733 \\
\hline
\end{tabular}


Beberapa kemungkinan terkait dengan hasil yang tidak signifikan dalam penelitian ini yaitu pertanyaan yang digunakan sangat sensitif sehingga banyak responden yang tidak memberikan jawaban dengan kenyataan yang terjadi. Secara singkat penelitian ini menunjukkan bahwa verifikasi laporan keuangan tidak mempengaruhi ada atau tidaknya praktek penyuapan oleh perusahaan. Hal tersebut dikarenakan lebih dari setengah responden tidak melakukan verifikasi laporan keungan namun tidak banyak responden yang melakukan praktek penyuapan.

\section{Simpulan dan saran}

Penilitian ini bertujuan untuk mengetahui apakah ada hubungan verifikasi laporan keuangan terhadap tindakan suap pada UMK. Secara statistik, penelitian ini tidak memberikan bukti bahwa UMK yang sudah melakukan verifikasi atas laporan keuangan cenderung tidak terlibat dalam tindakan suap. Keterbatasan dalam penelitian ini adalah jawaban dari kuesioner menggunakan data biner (ya dan tidak) untuk variabel independen dan dependennya. Pertanyaan-pertanyaan dalam kuesioner yang digunakan sangat sensitif sehingga banyak responden yang tidak mengutarakan jawaban dengan kenyataan yang terjadi. Penelitian mendatang diharapkan untuk lebih spesipik dalam menghubungkan verifikasi dengan suap dikarenakan praktek suap merupakan topik yang sensitif.

\section{Daftar Rujukan}

Astuti, N. P. (2014). Analisis Persepsi UMKM atas Pelaporan Keuangan. Thesis Universitas Malang.

Cuervo, A., \& Cazurra. (2007, August). The effectiveness of laws against bribery abroad. Journal of International Business Studies.

Farooq, 0., \& Shehata, N. F. (2018). Does external auditing co $\mathrm{m}$ bat corruption? Evidence fro m private firms. Managerial Auditing Journal. Retrieved from https://doi.org/10.1108/MAJ-08-2017-1634

Febrianty, Febrianty, and Divianto Divianto. "PENGARUH PEMAHAMAN PELAKU UKM DALAM MENYUSUN LAPORAN KEUANGAN TERHADAP IMPLEMENTASI LAPORAN KEUANGAN BERDASAR SAK ETAP DENGAN PERSEPSI PELAKU UKM SEBAGAI MODERATING VARIABLE." International Journal of Social Science and Business 1.3 (2017): 166-176.

Hakim, A. (2019). Prospek kriminalisasi pemberian sesuatu kepada dokter non pegawai negeri oleh perusahaan farmasi.

Haryono. (2015). Risywah (suap-menyuap) dan perbedaannya dengan hadiah dalam pandangan hukum islam.

Healy, P., \& Serafeim, G. (2016). An analysis of firms' self-reported anticorruption efforts. The Accounting Review, 489-511.

Henzani, M. Danny. "Pengaruh Moralitas Dan Motivasi Penyusun Laporan Keuangan SKPD Terhadap Kecenderungan Kecurangan Laporan Keuangan (Studi empiris pada pemko Kota Sawahlunto)." Jurnal Akuntansi 1.3 (2013).

Khalil, S. (2015). Disclosure Standards, Auditing Infrastructure, and Bribery Mitigation. J Bus Ethics, 379399. doi:10.1007/s10551-014-2321-6.

Lakhe, B. K., \& Wai, S. H. (2011). Audit from Audit Exempted Small and Medium-sized Entities (SMEs) in Sweden. Student Umeå School of Business.

Marbun, A. N. (2017, Maret). Suap di Sektor Privat: Dapatkah Dijerat? 3.

Mulyani, S. (2014). Faktor-faktor yang mempengaruhi kualitas laporan keuangan pada umkm di kabupaten kudus. Universitas muria kudus, 137-149.

Omar Farooq, N. F. (2017). Does External auditing combat corruption? Evidance from private firms. Managerial Auditing Jurnal . 
Perangin-Angin, Santa Clara. PENGARUH AUDIT INTERNAL TERHADAP PENCEGAHAN KECURANGAN (FRAUD)(Studi Kasus pada PT. Kereta Api Indonesia Bandung). Diss. Universitas Widyatama, 2015.

Pongoh, M. (2013). Analisis laporan keuangan untuk menilai kinerja keuangan pt. Bumi resources tbk. Fakultas ekonomi dan bisnis, jurusan akuntansi universitas sam ratulangi manado, 669-679.

Puspapertiwi, S. (2014, Juni). Korupsi Siemens Aktiengesellschaft dalam United Nations-Oil For Food Programme (Un-Offp) di Irak. Indonesian Journal of International Studies (IJIS) 31, 1.

SBM, N. (2012, Juli). Korupsi dan faktor-faktor yang mempengaruhinya di indonesia. Media ekonomi dan manajemen, 26.

Sohail. (2014). The Impact of Corruption on Firm Performance: Evidence from. Public Policy and Administration Research, Vol.4, No.9, 2014 .

Wahyudi, G. (2011). Kajian tentang penyuapan sebagai salah satu bentuk tindak pidana korupsi.

Wahyudi, P. (2016, Desember 27). Verifikasi atau Audit. Retrieved Oktober 10, 2018, from Satuan Pengawasan Internal: http://spi.uin-alauddin.ac.id/index.php/2016/12/27/verifikasi-atau-audit/

Wu, X. (2009). Determinants of Bribery in Asian Firms: Evidence from the World Business Environment Survey. Journal of Business Ethics, 75-88. doi:10.1007/s10551-008-9871-4 